\title{
A POLÍTICA DE QUALIFICAÇÃO DO TRABALHO DOCENTE: FORMAÇÃO E CAPACITAÇÃO EM SERVIÇO.
}

\author{
Prof. Dr. Pedro Ganzeli ${ }^{1}$
}

\section{Resumo}

Um dos principais problemas a ser enfrentado pelas políticas de qualificação em serviço do trabalho docente é a de proporcionar espaços que respeitem o universo local. Essa comunicação busca justamente contribuir para esse debate analisando a implementação de uma política de qualificação em serviço e de seus impactos no cotidiano da unidade escolar. Para tanto recorremos a uma pesquisa por nós realizada em uma Secretaria Municipal de Educação, compreendendo a política pública como sendo o Estado em ação. A metodologia utilizada foi da pesquisa-ação, o que favoreceu a compreensão dos diferentes aspectos que influenciaram a construção da autonomia pelos agentes educacionais envolvidos na pesquisa.

\section{Introdução}

No Brasil podemos distinguir duas formas principais de qualificar o trabalho do professor que está atuando na sala de aula: a) capacitação em serviço que compreende a oferta de cursos temáticos ou de áreas de conhecimento ao conjunto de professores; e a formação em serviço que, por sua vez, é realizada pela freqüência do professor em cursos que lhe propicia a continuidade nos estudo, possibilitando a progressão na carreira. Nos anos de 1990, ocorreram profundas mudanças na legislação que rege a educação nacional, provocando a intensificação nas políticas de qualificação em serviço dos profissionais da educação.

A promoção de programas de qualificação tendo em vista o conjunto de professores dos diferentes sistemas educacionais existentes no país, gerou certa polêmica incomodo entre os educadores (Educação e Sociedade, 2001), pois ao serem concebidos para atenderem a todos os sistemas de ensino, deixaram de trabalhar com os aspectos mais específicos do universo local. Cabe observarmos que não se trata de negar a importância desses programas, mas analisar os seus limites e possibilidades no âmbito da unidade escolar, esse é o nosso objetivo nessa comunicação.

Para analisar os processos de capacitação do corpo docente no âmbito da unidade escolar recorremos a uma pesquisa que realizamos na rede municipal de ensino do município de Indaiatuba, estado de São Paulo no período compreendido entre os anos de 2002 a 2004.

Inicialmente faremos uma breve contextualização da educação brasileira nos anos de 1990 e da rede municipal de ensino na qual foi implementada a pesquisa. Em seguida apresentaremos as características gerais da pesquisa e, finalmente, analisaremos a política de capacitação promovida pelos órgãos centrais da educação municipal e a dinâmica de

\footnotetext{
${ }^{1}$ Programa de Pós-Graduação - Faculdade de Ciências e Letras - Unesp/CAr.

Programa de Pós-Graduação - Faculdade de Educação - Unicamp

pganzeli@terra.com.br
} 
qualificação vivenciada em uma unidade escolar que abrigou uma experiência diferenciada proposta pela pesquisa.

\section{Breve contextualização da educação escolar no município}

O Brasil é uma República Federativa, o que significa uma co-responsabilização entre a União, os Estados e os Municípios, na definição, condução e manutenção de políticas públicas, porém, apesar das disposições sobre o assunto, presente na Constituição Federal de 1988, ainda é grande o debate entre a União, os 27 estados e os 5.560 municípios brasileiros sobre as formas de cooperação que deve ocorrer entre eles nas diferentes áreas de atuação da administração pública.

$\mathrm{Na}$ área da educação, historicamente, a União se responsabilizou pelo ensino superior (Universidades e Faculdades), enquanto Estados e Municípios mantinham a educação básica (educação infantil - 0 a 6 anos; ensino fundamental - 7 a 14 anos; ensino médio - 15 a 17 anos). Existem Estados e Municípios que, por possuírem grande dinamismo econômico, criaram as suas Universidades e Faculdades públicas.

No caso específico do Estado de São Paulo, no qual se localiza o município de Indaiatuba, a educação escolar foi predominantemente responsabilidade do governo estadual, sendo pouca a participação dos municípios, em especial, da etapa obrigatória da educação básica, qual seja, o ensino fundamental.

Em 1996 ocorreram várias e significativas modificações na legislação da educação nacional: aprovação da Lei de Diretrizes e Bases da Educação Nacional (Lei n 9394) e a Emenda Constitucional $n^{\circ} 14$. Para os objetivos desse trabalho nos ateremos a Emenda Constitucional que, entre outras alterações criou o Fundo de Manutenção e Desenvolvimento do Ensino Fundamental e Valorização do Magistério - FUNDEF - no âmbito de cada Estado, de natureza contábil, esse fundo é composto por parcelas de impostos recolhidos por Estado e Municípios. A distribuição dos recursos é realizada conforme o número de alunos matriculados no ensino fundamental em cada rede de ensino (estadual ou municipal). A União passou a participar do FUNDEF através de complementações aos fundos estaduais que não alcançam o custo-aluno básico definido anualmente para todo o território nacional. Entrando em vigor no dia 01 de janeiro de 1998, ele se mostrou um vigoroso indutor da criação ou mesmo ampliação de redes e sistemas municipais de ensino, transformando de forma significativa a estrutura e o funcionamento da educação municipal (GIUBILEI,2001; OLIVEIRA, 1999;).

No caso do Estado de São Paulo houve um forte movimento de transferência de escolas da rede estadual para as recém criadas redes municipais de ensino. Em 1996 a rede estadual detinha 87,5\% das matrículas do ensino fundamental (5.078.539 alunos), enquanto que a rede municipal de ensino possuía $12,5 \%$ das matrículas nessa etapa da educação básica (726.704 alunos). Após dois anos da criação do FUNDEF, a rede estadual de ensino contava com 4.126.897 alunos, representando 74,2\% das matrículas e a rede municipal de ensino ampliou para 1.437 .870 o número de alunos, representando $25,8 \%$ das matrículas.

O município de Indaiatuba está localizado na Região Metropolitana de Campinas, considerada uma das regiões mais desenvolvidas economicamente do país. Indaiatuba 
contava no ano de 2001 com um parque industrial com 618 indústrias, seu comércio era composto por 1.168 estabelecimentos comerciais e 789 empresas de prestação de serviços. Sua população em 2004 foi estimada em 166.683 habitantes. Até o ano de 1997 a educação pública no município de Indaiatuba, atendia 20.654 alunos na rede estadual de educação (ensino fundamental e ensino médio) e 2.225 alunos matriculados na rede municipal de ensino (educação infantil).

Impulsionada pela pressão por mais escolas, bem como pelas últimas alterações promovidas pela criação do FUNDEF, a administração municipal viu a necessidade de expandir sua rede de ensino para além da educação infantil, criando o Sistema Municipal de Ensino com a aprovação da Lei Municipal $n^{\circ} 3.507$ de 8 de janeiro de 1998. Esta lei carrega muita semelhança com os dispositivos presentes na LDB, Lei $n^{\circ} 9394 / 96$, sobre os Sistemas Municipais de Educação.

O censo escolar de 2003 apontou no município um contingente de 25.132 alunos matriculados na rede estadual de ensino (ensino fundamental e ensino médio) e de 14.336 alunos matriculados na rede municipal de ensino (educação infantil, ensino fundamental).

Tomando como base o ano de 1997, um ano antes da municipalização do ensino, constatamos um crescimento de $544,3 \%$ no número de alunos matriculados na rede municipal de ensino, em relação ao ano de 2003. Novas funções, novas construções, novos alunos, novos professores, novos funcionários, nova legislação, alterações essas que provocaram a necessidade de se repensar toda à estrutura organizacional, financeira e pedagógica do sistema municipal de ensino, de forma a evitar a sua fragmentação, tão comum e prejudicial ao desenvolvimento da educação pública brasileira.

Foi nesse contexto de forte transformação que elaboramos, com a participação de dirigentes da SEME, o projeto Potencialização da Autonomia da Gestão Escolar Municipal, dentro do Programa Especial de Política Pública da Fundação de Amparo a Pesquisa do Estado de São Paulo - FAPESP, tendo como norte a construção de política educacional com autonomia e, ao mesmo tempo inovadora que atendesse as necessidades da rede municipal de ensino.

\section{Potencialização da Autonomia da Gestão Escolar Municipal}

A pesquisa "Potencialização da Autonomia da Gestão Escolar Municipal" se propôs a implementar ações na rede municipal de educação que potencializassem a capacidade dos agentes educacionais nos processos de formulação, acompanhamento e avaliação de políticas educacionais com autonomia e qualidade. Nosso problema era o de partindo dos saberes historicamente construídos pelos formuladores de política no município, propor "práticas descentralizadoras" em um sistema educacional predominado por "práticas centralizadoras".

Esta pesquisa orientou-se por quatro princípios básicos, a saber: princípio da historicidade das experiências realizadas pelos agentes educacionais da rede municipal de ensino. Esse princípio permitiu que as ações propostas tivessem como ponto de partida, o saber já acumulado por todos aqueles que trabalhavam com o ensino municipal. Dessa 
forma, buscou-se reconhecer certas identidades entre a memória, ou seja, o já realizado e as novas ações propostas pelo projeto; princípio da participação de todos os envolvidos com a rede municipal de ensino. A participação foi entendida como a capacidade do sujeito interferir nos processos decisórios da política educacional. Nesse sentido, a participação foi vista como um processo de aprendizagem que, como qualquer outro processo de aprendizagem, necessitou de espaço e tempo para que ocorresse; princípio da realidade local, expresso pelas condições presentes no espaço social, político, econômico e pedagógico no qual foi implementada a pesquisa. Este princípio orientou nosso olhar sobre os limites e as possibilidades presentes na realidade local. Garantiu a proposição de ações que respeitassem o tempo histórico da realidade na qual foram implementadas. Dessa forma as ações estiveram impregnadas de realidade local, tornando-se relevantes para todos os agentes educacionais do ensino municipal; princípio teleológico, que buscou a produção de uma visão de futuro entre os sujeitos envolvidos com a pesquisa, em especial os agentes educacionais, possibilitando ações comprometidas com a construção de uma sociedade verdadeiramente democrática.

As ações para a implementação desse projeto de pesquisa foram organizadas através de 7 subprojetos, que dialogaram entre si, a saber: subprojeto 1 - Implementação da Câmara de Educação na estrutura organizacional da secretaria municipal de educação; subprojeto 2 - Capacitação do corpo docente e de funcionários da secretaria municipal de educação; subprojeto 3 - Implementação de Sistemas Informatizados; subprojeto 4 Sistematização de dados históricos da educação no municipal; subprojeto 5 - Análise da legislação educacional do município; subprojeto 6 - Produção de registros em Vídeos e Textos do cotidiano escolar; subprojeto 7 - Potencialização do Conselho de Escola.

Os subprojetos foram sendo realizados de forma a viabilizarem a interação entre si, favorecendo a potencialização dos resultados e evitando ações sobrepostas. Estes subprojetos buscaram atender a três áreas da gestão escolar: sistematização de dados (históricos, estatísticos, outros) que subsidiem o processo de redimensionamento e gestão da Proposta Pedagógica Global da Secretaria Municipal de Educação de Indaiatuba (SEME) e os Planos Escolares; qualificação em serviço para atualização dos funcionários, professores e especialistas, de forma a garantir a implementação de ações inovadoras na SEME. Produção de materiais (informativos, didáticos, outros) que auxiliem o processo de gestão da SEME.

A integração entre os subprojetos foi proporcionada por meio de reuniões gerais, quando cada subprojeto apresentava as ações realizadas e os problemas a serem enfrentados, sendo estes debatidos pelo grande grupo, favorecendo a busca de soluções coletivas. Garantiu-se assim uma prática que teve na participação de todos, seu aspecto fundamental.

Cada subprojeto formou um grupo de pesquisa constituído por pesquisadores externos e agentes educacionais da rede municipal de educação, em especial aqueles pertencentes ao quadro de dirigentes (Diretor de Departamento, Supervisores de Ensino, Orientadores Educacionais). Entendemos que essa forma de composição das equipes possibilitou a produção e transferência de conhecimento entre os participantes do processo de pesquisa. Essa forma de organização do trabalho corresponde ao que BARRIER (2002) 
considera como pesquisador coletivo. Segundo o autor "o pesquisador coletivo é um gruposujeito de pesquisa constituído por pesquisadores profissionais (provenientes de organismos de pesquisa ou de universidades) e por membros, que gozam de todos os privilégios (mas particularmente implicados), da população vinculada à investigação participativa". (p.103). $\mathrm{O}$ grupo de pesquisadores era formado por 20 pessoas, sendo 12 ligadas à secretaria municipal de educação e 8 professores externos. Este grupo variou muito no decorrer dos trabalhos.

Um aspecto importante a ser destacado quando assumimos a pesquisa-ação em um projeto que teve a autonomia como objetivo relacionou-se a própria autonomia das decisões tomadas pelos agentes educacionais da rede municipal de ensino. Os pesquisadores externos assumiram a função de observadores da política implementada. Não observação passiva, mas ativa, pois as propostas e críticas formuladas pelos pesquisadores externos favoreceram a reflexão dos agentes educacionais e, por conseguinte, maior clareza sobre a estrutura e funcionamento da rede municipal de ensino. De outra forma não seria autonomia.

João Barroso(1996) defende que a autonomia deve ser entendida para além da perspectiva jurídico-administrativa, avançando até uma perspectiva sócio-organizacional, como uma propriedade construída pelos agentes educacionais. Vista dessa forma a autonomia, segundo o autor consiste "em um jogo de dependências e interdependências que os membros de uma organização estabelecem entre si e com o meio envolvente com o fim de estruturarem a sua acção organizada em função de objetivos próprios, coletivamente assumidos" (p.20).

Passemos a seguir a analisar a lógica de qualificação promovida pelos órgãos centrais da secretaria municipal de educação de Indaiatuba e a dinâmica de apropriações realizadas pelos professores no âmbito da unidade escolar, buscando compreender o processo de construção de autonomia.

\section{Política de qualificação em serviço da Secretaria Municipal de Educação de Indaiatuba}

Ao iniciarmos a pesquisa em janeiro de 2002, toda a transformação vivenciada pela rede municipal de educação, conforme antecipamos, passou a fazer parte das reflexões do grupo de gestores que trabalhavam nos órgãos centrais da secretaria municipal de educação. As reuniões coletivas proporcionadas pela pesquisa obrigaram as equipes pertencentes a diferentes setores e departamentos a discutirem seus problemas de forma integrada. Cada setor ou departamento preocupava-se, até então, em atender o específico de seu trabalho, sem uma compreensão mais clara sobre o significado das tarefas realizadas sobre o processo de construção da Proposta Pedagógica Global da Secretaria Municipal de Educação de Indaiatuba. A visão geral ficava restrita a secretária municipal de educação e a alguns chefes de departamento. Uma conseqüência foi a progressiva tomada de consciência por parte dos agentes educacionais em relação a necessidade de integração entre as ações dos diferentes setores e departamentos.

As ações de qualificação em serviço envolviam reuniões pedagógicas, encontros dos 
educadores da rede municipal de ensino, Horário de Trabalho Pedagógico Coletivo na Unidade Escolar, oficinas pedagógicas, participação dos educadores em simpósios, cursos de curta duração e freqüência a cursos de formação promovidos por Universidades e Faculdades. Essas ações buscaram desenvolver a Proposta Pedagógica Global.

A rede municipal de ensino de Indaiatuba era constituída em 2004 por 13 (treze) Creches que atendiam 1.030 alunos na faixa etária do 0 (zero) aos 3 (três) anos de idade; 21 (vinte e uma) Escolas Municipais de Educação Infantil - EMEIs, com a oferta de 5.059 vagas para alunos na faixa etária dos 4 (quatro) aos 6 (seis) anos de idade (duas dessas atendiam também crianças de 0 a 3 anos); e 18 (dezoito) Escolas Municipais de Ensino Fundamental - EMEFs, que atendiam 8.130 alunos na faixa etária dos 07 (sete) aos 10 (dez) anos $^{2}$. As Creches e as EMEIs eram dirigidas pelas Coordenadoras de Unidades Escolares (CUEs), professoras formadas no ensino médio na modalidade Magistério e que não possuíam curso em Pedagogia e as EMEFs, por suas vez, eram geridas pelas Diretoras de Unidades Escolares (DUEs) que possuíam o curso em Pedagogia.

As orientações em relação a organização das unidades escolares eram realizadas por reuniões quinzenais entre os dirigentes dos órgãos centrais da secretaria municipal de educação e a gestoras das unidades escolares. Essas reuniões eram consideradas como um espaço privilegiado de capacitação dos gestores nos diferentes aspectos de sua prática.

Ao iniciarmos a pesquisa em 2002, foi realizado um diagnóstico sobre a situação da política de qualificação implementada pela SEME, constatando-se que: a) no ano de 2002, mais de $50 \%$ dos Professores não possuíam formação em Pedagogia e mais de $90 \%$ dos Monitores $^{3}$ não possuía formação em nível médio, Magistério; b) $\mathrm{O}$ desenvolvimento escolar do Ensino Fundamental apontou 10, 2 \% de retenção no ano de 2001 e 7,9\% em 2002; c) o desenvolvimento dos alunos pré-escolares em 2001 gerou dificuldades no ano de 2002 quanto à continuidade de estudos de $20 \%$ dessas crianças no que diz respeito à alfabetização e ao desenvolvimento cognitivo; d) 33\% dos Professores da Educação Infantil sugeriram ampliar estudos sobre o desenvolvimento cognitivo e $24 \%$ deles solicitaram mais estudos quanto às fases do desenvolvimento, especialmente sobre a moralidade infantil; e) $33 \%$ dos Professores do Ensino Fundamental solicitaram ampliação de estudos quanto ao desenvolvimento moral, $26 \%$ pediram mais estudos quanto à interdisciplinaridade e $19 \%$ solicitaram estudos sobre as estruturas lógicas elementares.

Nas reuniões gerais da pesquisa quando do relato sobre o andamento do subprojeto 2 (Capacitação), surgiam várias indagações relativas às ações de qualificação até então implementadas. Para nossos objetivos destacaremos três. A primeira relacionou-se a ausência de ferramentas para o acompanhamento e avaliação das ações de qualificação realizadas, pois, até então, a maior preocupação era a de garantir a oferta de cursos considerados necessários para promover a qualidade do ensino, sem, no entanto, criarem formas apropriadas para dimensionar os impactos dessas ações no cotidiano da sala de aula.

\footnotetext{
2 No Brasil o Ensino Fundamental, nesse período, possuía 8 anos escolares. As escolas municipais em Indaiatuba atendiam as crianças apenas nos primeiros 4 anos do Ensino Fundamental. Em três Escolas Municipais de Ensino Fundamental, existiam classes que abrigavam a Educação de Jovens e Adultos (EJA), alunos com mais de 15 anos de idade e que não haviam realizado o Ensino Fundamental.

${ }^{3}$ Funcionários que atendem as crianças de 0 a 3 anos nas Creches Municipais.
} 
A segunda indagação referia-se ao modelo de capacitação implementada que pressupunha a presença dos CUEs e DUEs nos diferentes cursos de capacitação, assumindo assim a tarefa de "multiplicador" dos conteúdos trabalhados junto aos professores e funcionários das respectivas unidades de ensino. Questionamos os limites desse modelo, pois os gestores passaram a assumir uma carga excessiva de freqüência aos cursos e transmissão de informações. A terceira indagação foi fruto de muita controvérsia relacionada ao termo "capacitação", pois este termo era utilizado pelos agentes educacionais de forma indiscriminada para ações distintas, o que dificultava a compreensão mais clara sobre os efeitos das "capacitações" realizadas.

Assim, após alguns debates acalorados, ficou decidido que a equipe técnicapedagógica explicitasse através de critérios objetivos o significado do termo "capacitação", definindo três ordens de capacitação segundo a natureza e o conteúdo desenvolvido nas ações: a) Cursos de formação e habilitação profissional; b) Capacitações essencialmente pedagógicas e de aprofundamento dos conteúdos curriculares; c) Capacitações priorizararam a potencialização da gestão escolar propriamente dita.

As "ações capacitadoras" do período, principalmente as essencialmente pedagógicas, fortaleceram o vocabulário e a compreensão pedagógica dos educadores, em relação à Proposta Pedagógica Global, ampliando-lhes o entendimento sobre os processos de conhecimento e de ensino, qualificando sua prática educativa, a partir dos objetivos pretendidos e assumidos pelo ensino municipal, em cada uma de suas modalidades de ensino. Tal afirmação comprova-se pela definição, disseminação e significativo alcance das metas anuais de aprendizagem, decididas em consenso em cada modalidade de ensino, respeitando-se as diferentes fases de desenvolvimento dos alunos. Cabe ressaltar que as metas de aprendizagem da Educação Infantil foram decididas em diálogo com o Ensino Fundamental, analisando inclusive, os dados de promoção e retenção, presentes principalmente nas primeiras séries. Por sua vez, as séries consecutivas do Ensino Fundamental, fizeram o mesmo, fato que demonstra a prática de ações integradas que contribuíram substancialmente para a continuidade de estudos dos alunos.

O conjunto das ações capacitadoras mobilizou também a reconceituação da totalidade do trabalho desenvolvido pela secretaria municipal de ensino, possibilitando aos agentes educacionais uma visão mais integral e integrada da rede municipal de educação.

Se por um lado houve relativos ganhos na metodologia e didática das ações educativas, por conta das inúmeras capacitações essencialmente pedagógicas e de aprofundamento dos conteúdos curriculares realizadas, por outro foram notórias as dificuldades por parte das equipes escolares em planejar, administrar e organizar o trabalho como um todo. Por esse motivo, no ano de 2004 o oferecimento de capacitações essencialmente pedagógicas, ocorreram num ritmo mais compassado, dando espaço maior para o processo de elaboração dos Planos Escolares e para o acompanhamento do desenvolvimento da gestão escolar.

Cabe, mesmo que de forma abreviada, analisarmos como as "ações de capacitação" influenciaram a dinâmica da unidade escolar, para tanto, vamos nos reportar ao subprojeto 
6 - registros em vídeo e texto do cotidiano escolar, implementado em uma unidade escolar de Ensino Fundamental.

Diante da existência de formas variadas de registro das experiências, pensou-se, aqui, privilegiar as gravações em vídeo como maneira mais adequada de criar esses mecanismos de estímulo ao debate. Sugeriu-se que essas gravações fossem realizadas em condições que permitissem o registro o mais possivelmente fiel das situações abordadas, o que implicou em pensar na operação da aparelhagem pelos próprios agentes do processo em curso: por exemplo, nas situações dentro da sala de aula, o agente do registro, idealmente, foi o próprio docente, na impossibilidade, o coordenador pedagógico da escola.

Para a implementação do subprojeto 6 foi constituída uma equipe formada por dois pesquisadores 'externos', ligados a universidade, e dois pesquisadores 'internos', pertencentes ao quadro dirigente dos órgãos de gestão da secretaria municipal de educação.

A equipe de implementação responsabilizou-se em proporcionar as condições para que a escola realizasse os registros em vídeo. A relação entre a equipe de implementação e a escola se deu exclusivamente, por meio de reuniões com o corpo dirigente da unidade escolar (diretor escolar e coordenadoras pedagógicas) ficando esses responsáveis pelo desenvolvimento do projeto no âmbito da unidade escolar. Buscamos assim favorecer maior liberdade possível, e reduzir os possíveis constrangimentos, com a presença de pessoas estranhas à unidade escolar.

Enfatizou-se a necessidade dos dirigentes da unidade escolar em esclarecer a equipe escolar (dirigentes, professores e funcionários) da importância do registro das atividades desenvolvidas na escola para que, a própria equipe escolar, pudesse melhor compreendê-las e, no desenvolvimento e conquista de sua autonomia, pudesse ser capaz de formular soluções adequadas e viáveis para os problemas do cotidiano escolar, do planejamento e da gestão dos vários procedimentos na unidade escolar. Era vital para o sucesso do subprojeto que os professores não viessem a entender as atividades propostas como mais uma tarefa a ser cumprida como mais uma obrigação mas que se garantisse o seu envolvimento efetivo naquilo que se pretendia realizar. Esta estratégia se mostrou muito eficaz. Segundo relato dos próprios professores, foi grande a apreensão entre os mesmos quando souberam que poderiam ser filmados, apreensão essa só amenizada quando informados que quem decidiria o que filmar e quando, seria eles mesmos.

A seleção da Escola Municipal de Ensino Fundamental "Prof a Maria Benedicta Guimarães" para o início dos trabalhos, se deu pelos seguintes critérios: é localizada em um dos bairros mais populosos do município; possui boa infra-estrutura, contando com quadra coberta, o que facilita as filmagens externas; é grande a participação da comunidade no dia a dia da escola; foi a primeira escola municipalizada, fatores que, a nosso ver, favoreceriam um estudo dessa natureza. Integram a escola 36 professores, atendendo a aproximadamente, 750 alunos na faixa etária de 7 a 10 anos (quatro primeiras séries do ensino fundamental).

O primeiro ano de registros em vídeo teve um caráter experimental, sem roteiros pré-definidos, possibilitando a adaptação da comunidade escolar com essa inovação em seu cotidiano. No final do ano foi possível organizar os registros em três tipos: foram realizados 9 registros de reuniões pedagógicas; 3 registros de eventos (científicos e culturais); e 16 registros de atividades didáticas (registros do cotidiano em sala de aula). Pretendia-se 
fazer uma edição com a síntese dos conteúdos registrados no decorrer do ano, porém essa idéia foi abandonada, pois cada registro possui uma tal especificidade que impedia uma organização posterior dos seus conteúdos.

Essa dificuldade, porém, fez com que o grupo refletisse sobre a necessidade dos agentes educacionais planejarem o processo de filmagem, ou seja, garantir um registro que tivesse um eixo norteador, em especial, os registros de sala de aula. Assim, a diretora e as coordenadoras se comprometeram em planejar, com a participação dos professores, um cronograma de registros que contemplasse três momentos básicos do processo pedagógico, a saber: a) preparação das atividades didáticas a serem implementadas na sala de aula, prevendo-se para essa tarefa o espaço das reuniões do Horário de Trabalho Pedagógico Coletivo (HTPC); b) O registro em vídeo das atividades didáticas desenvolvidas em sala de aula; c) avaliação das atividades didáticas em reunião do HTPC, logo após a sua realização.

A exigência de organizar uma seqüência de atividades pedagógicas a serem elaboradas - executadas - avaliadas, gerou um novo olhar dos agentes educacionais da unidade escolar em relação à organização das ações dentro e fora da sala de aula. Assim, foi alterada a estrutura das reuniões de HTPCs de forma a garantir maior efetividade da proposta pedagógica da escola. Até então as reuniões de HTPCs possuíam uma programação definida em função dos cursos de capacitação previstos no calendário escolar. O tempo de discussão limitava-se ao conteúdo específico daqueles cursos. Ao propor a discussão dos registros em vídeo a realidade da sala de aula invadiu as reuniões de HTPCs de tal forma que obrigou a sua reorganização, ampliando o tempo para discussão e avaliação das atividades didáticas.

Os registros em vídeo produzidos nos anos de 2002 e 2003 foram editados e organizados em um acervo composto por 31 fitas em VHS, transcritas e catalogadas em fichas criadas pelos agentes educacionais o que garante a consulta rápida e dinâmica ao conteúdo, especialmente os registros das reuniões pedagógicas.

Podemos dizer que o trabalho de registro em vídeo possibilitou o desenvolvimento e a ampliação das competências dos agentes educacionais ao possibilitar um movimento de auto-conhecimento, no que se refere a sua historicidade, sua organização e seu profissionalismo. Alterou a rotina de capacitação mobilizando os saberes produzidos no espaço local pelos agentes educacionais da unidade escolar, integrando-os de forma consistente e realista aos conteúdos trabalhados nos cursos e reuniões pedagógicas, organizadas a partir dos órgãos centrais da secretaria municipal de educação.

\section{Conclusão}

Os resultados da pesquisa Potencialização da Autonomia da Gestão Escolar Municipal em Indaiatuba se traduzem em ganhos de consciência dos agentes educacionais, em relação ao processo de formulação, acompanhamento e avaliação de políticas educacionais, em especial, àquelas voltadas para a qualificação em serviço do corpo docente.

Nos deparamos com o Estado em ação. O aparelho de Estado foi se transformando, se tornando mais complexo, colocando novos desafios para os agentes educacionais. Não se 
tratava apenas de qualificação em serviço do "outro" mas de todos os envolvidos no processo, especialmente os responsáveis pela elaboração e promoção da política de qualificação em serviço.

A escola não apenas reproduz os valores da sociedade contemporânea mas também produz novas formas de pensar e agir. Neste sentido, ela deve ser compreendida como uma 'unidade social'. A escola determina tipos específicos de comportamentos e formas de associações, "suas relações com as instituições sociais e a circunstância de receber estatuto, normas e valores da sociedade, não nos devem tornar incapazes de analisar o que nela se desenvolve como resultado da sua dinâmica própria. Os elementos que integram a vida escolar são em parte transpostos de fora; em parte redefinidos na passagem, para ajustar-se às condições grupais; em parte desenvolvidos internamente e devido a estas condições. Longe de serem um reflexo da vida da comunidade, as escolas têm uma atividade criadora própria, que faz de cada uma delas um grupo diferenciado dos demais" (Candido, 1987, pp. 12-3, grifo do autor).

O aprendizado que ocorreu entre os pesquisadores não se limitou a reprodução de um determinado modelo de qualificação em serviço mas, principalmente, na ampliação do olhar pedagógico em relação a produção de saberes escolares e sobre a produção de ferramentas de acompanhamento e avaliação a partir de novas necessidades. Os fatores administrativos, financeiros, pedagógicos e políticos estiveram sempre presentes no processo de qualificação em serviço, hora viabilizando propostas inovadoras, hora limitando a ação dos agentes educacionais. Fatores que não foram negados ou ignorados pelo pesquisador coletivo, tratou-se de compreendê-los, explorando ao máximo as condições concretas da realidade em que trabalhamos.

\section{Referências Bibliográficas}

Barbier, R. (2002). A pesquisa-ação. Brasília:Plano Editora.

Barroso, J. (1996). Autonomia e Gestão das Escolas. Lisboa, Ministério da Educação (Estudo prévio realizado de acordo com o Despacho nº130/ME/96).

Brasil. (1996). Emenda Constitucional $n^{\circ}$ 14. Modifica os art. 34, 208, 211 e 212 da CF e dá nova redação ao art. 60 do ADCT, de 12 de setembro de 1996.

Brasil (1996) Lei $N^{o}$ 9.394. Lei de Diretrizes e Base da Educação Nacional, 20 de dezembro de 1996.

Cândido, A. (1987). Tendências no Desenvolvimento da Sociologia da Educação. En L. Pereira y M. Foracchi. (Eds.). Educação e Sociedade. São Paulo: Companhia Editora Nacional.

Giubilei, S. (Ed.). (2001). Descentralização, Municipalização e Políticas Educativas. Campinas/SP: Alínea.

Educação \& Sociedade. (2001) Revista Quadrimestral de Ciência da Educação/ Centro de Estudos Educação e Sociedade (Cedes). Campinas, $3^{\mathrm{a}}$ Edição, No 68 V. XX.

Indaiatuba (Município).(1998) Lei Municipal $n^{\circ}$ 3.507, dispõe sobre o Sistema Municipal de Ensino. 
Ferretti, J. S. E., Milan, T. C. y Sanches, A. C. G. (Eds.) (2004). Proposta Pedagógica Global da Rede Municipal de Ensino. Indaiatuba, SP: Gráfica Caravela Ltda. 